\title{
DRESSING THE PART: GENDER, PERFORMANCE AND THE CULTURE OF LAW SCHOOLS
}

\author{
Fiona Cownie, Professor of Law, Keele University"
}

\section{Introduction}

This article forms part of a project to examine the culture of the discipline of law, and the professional identities of academic lawyers. In particular, it focuses on the practices of legal academics with regard to their everyday dress, using previously unpublished data about what legal academics choose to wear to reveal significant aspects of the culture of academic law and the lived experience of legal academics.

Clothes perform a major role in the construction of identity, and at the same time provide an excellent field for studying the ways in which people interpret a specific form of culture for their own purposes. ${ }^{1}$ In the context of the legal academy, choice of everyday dress reveals a number of ways in which legal academics construct their professional identities as "academic lawyer", "lecturer", "professor", and so on, as well as revealing some otherwise hidden aspects of the culture of academic law.

\section{Academic Examination of Everyday Dress}

The academic study of dress is still in its infancy, although, as Entwistle and Wilson note, over the last twenty years or so it has moved a long way from its previous marginal status, whereby it was regarded as being of intellectual interest only to anthropologists and otherwise unworthy of serious attention. ${ }^{2}$ This longstanding reluctance to take dress seriously has been reinforced by general societal norms, which require that we do not judge others by their appearance, as well as by the influence of the Cartesian mind/body dualism within the academy, with its emphasis upon reason and rationality, which has relegated the everyday dress choices of individuals to a matter of relative unimportance. ${ }^{3}$ The stereotype of the academic who exemplifies this scruffily dressed in out-of-date, unfashionable, badly-fitting clothes, is alive and well, as a recent series of articles in the press has made clear. ${ }^{4}$

* I would like to thank Phil Bielby (University of Hull), Tony Bradney (University of Sheffield) and Mandy Burton (University of Leicester) for their comments on an earlier version of this paper.

1 Crane, Fashion and Its Social Agendas: class, gender and identity in clothing (2000), p.1.

${ }^{2}$ Entwistle \& Wilson, 'Introduction: Body Dressing' in Entwistle \& Wilson (eds.), Body Dressing (2001), p.1.

3 Csordas, 'Introduction: the body as representation and being-in-the-world' in Csordas (ed.), Embodiment and Experience: the existential ground of culture and self (1994), p.7.

4 'Spruce Up' Guardian Education 17.12 .02 p.27; 'What Not to Wear at the Whiteboard' Guardian Education 24.02 .04 p.19; 'What Not to Wear if you Want to Get On' Times Higher 18.06.04 p.19; 'Ditch the Smocks - Dress to Impress' Times Higher 29.10 .04 p.54. I would like to thank Phil Bielby, Lecturer in Law at the University of Hull, for drawing my attention to some of this material. 
“Styles may shift, but academics' reputation for bad dress sense never changes. .."

"Sitting in an august body of academics recently, the woman chairing the event caught my attention. For not only was she gracious, authoritative without being bossy, well-informed and pleasant, she was also well dressed. . . Around her were the usual bunch of shabby men and women instantly recognisable as academics by their battered trousers, tieless shirts, scuffed brogues, shapeless frocks, haircuts unchanged for 25 years and general lack of style of any kind."6

Yet the academy is a much more fruitful site for the study of everyday dress than these somewhat disparaging remarks might suggest. In his analysis of the discipline of dress studies, William Keenan notes that many academic disciplines and sub-fields have a "hidden dress dimension". The examples he gives include the "going native" practices of anthropologists and sociologists, the "dress for success" manoeuvres of aspirants to join the academic executive class, and the image-management of the academic feminist. He goes on to observe that the possibilities for "community selfsurveys" by participant insiders of the dress code behaviours, beliefs and values of professional academics are endless. ${ }^{7}$ This article seeks to exploit some of those possibilities by revealing hitherto un-noticed aspects of dress practices in the contemporary law school, and examining their significance, in terms of the construction of the professional identities of academic lawyers and the culture of the discipline of law.

Although anthropologists have been engaged in the serious analysis of dress for many years, their work has usually focused on non-Western or "traditional" societies, and it was not really until the development of the discipline of cultural studies in the 1960s that a wider range of academics began to take a serious interest in dress practices, resulting in a burgeoning literature on fashion. ${ }^{8}$ Interest in the analysis of the body, which blossomed at the end of the twentieth century, focused attention on practices such as tattooing and piercing, but it is only recently that attention has turned to everyday dress practices. ${ }^{9}$ Yet everyday dress plays a large part in social interaction; dress helps to define a person's location in geographic and historic terms, and it also differentiates the individual from all others. ${ }^{10}$ It is frequently an indication of the social status of a person, and a symbol of economic position. In addition, gender distinctions are a crucial part of the

5 'What Not to Wear if you Want to Get On' Times Higher 18.06.04 p.19.

6 'Ditch the Smocks - Dress to Impress' Times Higher 29.10.04 p.54.

7 Keenan, 'Dress Freedom: the personal and the political' in Keenan (ed.), Dressed to Impress: looking the part (2001), p.183.

8 Keenan, 'Introduction: Sartor Resartus Restored: dress studies in Carlylean perspective' in Keenan (ed.), Dressed to Impress: looking the part (2001), pp.1-50

9 Entwistle \& Wilson, 'Introduction: Body Dressing' in Entwistle \& Wilson (eds.), Body Dressing (2001), p.3; de la Haye \& Wilson (eds.) Defining Dress: dress as object, meaning and identity (1999) chap.1.

10 Johnson \& Lennon, 'Introduction: appearance and social power' in Johnson \& Lennon (eds.), Appearance and Power (1999), p.1. 
construction of dress. ${ }^{11}$ In everyday life, dress is the insignia by which we read others and by which we are read, however ambivalent and unstable those readings may be. ${ }^{12}$ An extensive body of literature exists which indicates that clothing is an important cue in judgements of others, and can be used not only as an indicator of more obvious factors, such as social status, but can also affect perceptions which are particularly relevant in the context of the law school, such as competence and credibility. ${ }^{13}$

The communicative aspects of dress have been studied in a number of different ways. Lurie argued that dress could be interpreted like a language, complete with grammatical rules, while Davis argued that dress is more accurately characterised as being similar to music, emphasizing its suggestive and ambiguous nature. ${ }^{14}$ In the context of examining dress in the context of the culture of academic law and its contribution to the construction of the professional identities of academic lawyers, Entwistle's framework for the analysis of everyday dress is particularly useful. She starts with the idea that dress is a "situated bodily practice", which is embedded in the social world. ${ }^{15}$ Her work provides a bridge between theories of the body (which often overlook dress) and theories of fashion and dress (which often overlook the body). In terms of work on the body, the structuralist and poststructuralist analyses of writers such as Douglas, Foucault and Mauss have provided insights into how the body is rendered meaningful by culture. ${ }^{16}$ However, in general, as Entwistle points out, these writers tend to neglect the need to account for how structures result in actual embodied practices, with the result that individuals tend to be reduced to puppet-like actors. ${ }^{17}$ On the other hand, the work of phenomenologists like Merleau-Ponty, which explores the idea of the body as a site of culture, are helpful in suggesting ways in which the body can be understood as an actual practice; the self is located in a body, which itself is located in time and space. ${ }^{18}$ Entwistle draws on these two apparently irreconcilable traditions to construct her theory of dress as a situated bodily practice, which is both a social and a personal experience. She argues that a study of the dressed body requires an understanding both of the socially processed body, and the experiential

11 Barnes \& Eicher, 'Introduction' in Barnes \& Eicher (eds.), Dress and Gender: making and meaning in cultural contexts (1992), p.1.

12 Entwistle, 'The Dressed Body' in Entwistle \& Wilson, Body Dressing (2001), p.37.

13 See: Kwon, 'The Influence of Appropriateness of Dress and Gender on the SelfPerception of Occupational Attributes' (1994) 12(3) Clothing \& Textiles Research Journal pp.33-39 at p.33.

14 See: Lurie, The Language of Clothes (1981) \& Davis Fashion, Culture and Identity (1992).

15 Entwistle The Fashioned Body: fashion, dress and modern social theory (2000), Ch.1.

16 See, e.g. M. Douglas, Natural Symbols (1973); M. Douglas (ed.), Implicit Meanings: essays in anthropology (1979); M. Foucault, 'Body/Power' in Gordon (ed.), Power/Knowledge: selected interviews and other writings $1972-77$ (1980); Mauss, 'Techniques of the Body' 2(1) Economy and Society (1973), p.70-89.

17 Entwistle, 'The Dressed Body' in Entwistle \& Wilson, Body Dressing (2001), p.35.

18 Merleau-Ponty, The Primacy of Perception (1976). 
dimension of embodiment, whereby dress is translated into actual bodily presentation.

"Dress lies at the margins of the body, and marks the boundary between self and other, individual and society. This boundary is intimate and personal, since our dress forms the visible envelope of the self, and . . . serves as a visual metaphor for our identity; it is also social, since our dress is structured by social forces and subject to social and moral pressures." 19

Entwistle's insights prove particularly useful when combined with those of Goffman, whose exploration of the "presentation of self" also provides a useful framework for the examination of everyday dress practices. ${ }^{20}$ Goffman argues, in his theory of "impression management", that when individuals interact with others, they try to control the impression that the others receive of the situation. His analysis is concerned with the participant's dramaturgical problems of presenting an activity to others. ${ }^{21}$ In discussing impression management, Goffman also makes us aware of the importance of different spaces; the street, the office, the shopping-mall all operate with different "rules" which help to determine how we present ourselves and how we interact with others. The university law school is another such space, with its own particular cultural norms. Dress forms part of the microsocial order of such spaces, and is an important part of what Goffman terms "personal front", the items of "expressive equipment" that we most intimately identify with the performer. He tells us that these include sex, age and racial characteristics, speech patterns, posture, facial expressions, bodily gestures - and clothing. ${ }^{22}$ It is very clear that for Goffman, as for Entwistle, the dressed body is both the property of the individual and of the social world. It expresses our identity, but we manage our identities in relation to the different social situations we participate in. Thus, dress lies at the junction of culture and identity, and provides an excellent site for the examination of these concepts in relation to legal academia. Dress, as both these theorists would argue, is thus the result of a complex interaction between the individual and the social, between culture and identity.

In this context, we cannot ignore the insights of Bourdieu. He sees us as inhabiting a "habitus", that is to say, a context of custom, tradition, evaluation and response which significantly shapes our personal choices. Once acquired, the habitus allows us to generate practices which are adaptable to the differing social conditions we meet. ${ }^{23}$ Our position is also greatly affected by our command over various types of "capital". Dress is one mode of "symbolic capital" and a significant part of the sources of power available to us in our interactions with others. ${ }^{24}$ In their dress choices, individuals are reproducing their social position in the world, but doing this

19 J. Entwistle, 'The Dressed Body' in Entwistle \& Wilson, Body Dressing (2001), p.37.

20 E. Goffman, The Presentation of Self in Everyday Life (1990).

21 E. Goffman, The Presentation of Self in Everyday Life (1990), p.26.

22 Goffman, The Presentation of Self in Everyday Life (1990), p.34.

23 Bourdieu, Outline of a Theory of Practice (1977).

24 Bourdieu, The Field of Cultural Production: essays on art and literature (1993). 
through individual embodied actions. As Tseelon comments, there is "a dialectical dialogue between cultural categories and the people who inhabit them." 25 This is clearly reflected in the dress choices made within the context of the law school, which are made by individuals who belong to a particular "tribe" of academics, and a particular disciplinary culture. ${ }^{26}$

\section{The Project}

The empirical data discussed in this article is drawn from an extensive qualitative study of academic lawyers and the culture in which they live their professional lives. During the period between June 2001 and December 2002, I interviewed 54 legal academics working in university law schools in England. All the academics were involved in teaching on academic law courses, as opposed to vocational courses. ${ }^{27}$ The interviews were semistructured and lasted between one and two hours each; they were conducted on the basis of confidentiality; neither the names of individuals nor the identity of the institutions involved are revealed. All interviews were taped and a full transcript was produced of each one.

As with most qualitative studies, I do not make any claims that my sample of respondents is statistically representative of my subject as a whole. Indeed, that is not the point of the study. Like Colin Evans, in his two books on the culture of Modern Languages and of English in higher education, my interest is not with the question "How representative is this?" but with the question "What does it represent?" 28 Nevertheless, the methodology I used is a kind of theoretical sampling, directed at validity of findings, rather than representativeness of population. ${ }^{29}$ Thus the sampling was systematically carried through so that, as Finch and Mason argue, it is possible to justify a degree of generalization. ${ }^{30}$ Interview sites were chosen to reflect variations in institution, including both old and new universities, while individuals were selected to reflect differing status, experience and gender; since, on the basis of previous research, there were grounds for believing these factors could be significant in relation to the construction of the professional identities of academics and the culture of the law school. ${ }^{31}$ For the purposes of this study,

25 Tseelon, The Masque of Femininity (1997), p.3.

26 On disciplinary cultures, see: Becher \& Trowler Academic Tribes and Territories: intellectual enquiry and the culture of disciplines (2001); on the culture of academic law, see: Cownie, Legal Academics: culture and identities (2004), esp. chap.3.

27 Note that legal academics teaching on vocational courses tend to have particular dress practices, due to the necessity to 'model' legal practice for their students.

28 Evans, English People: the experience of teaching and learning English in British universities (1993), p.x.

29 'Theoretical sampling' is a term often associated with Glaser and Strauss' treatise on grounded theory, but its logic and practice has become part of a tradition of qualitative research.

30 Finch \& Mason, 'Decision-taking in the Fieldwork Process: theoretical sampling and collaborative working' in Burgess (ed.), Studies in Qualitative Methodology (1990), p.28.

31 On the importance of institutional diversity, see, for example: Clark, The Academic Life: small worlds, different worlds (1987); Henkel, Academic Identites and Policy Change in Higher Education (2000); Scott, The Meanings of Mass Higher Education (1995). On the importance of status see: Thorsen, 'Stress in 
I evolved three broad categories of experience: "early career" of up to ten years' experience; "mid-career" of ten to twenty years' experience and "experienced" with more than twenty years' experience. My respondents comprised eighteen experienced academics, fifteen mid-career and twentyone early career academics, giving a broad range. The spread of interviewees in terms of status also reflected McGlynn's findings about the ratio of senior/ unpromoted positions in relation to legal academia as a whole. ${ }^{32}$ The sample included thirty-five men and nineteen women, also giving roughly the same gender balance as that found by McGlynn. ${ }^{33}$

\section{Everyday Dress and Legal Academia}

The traditional response of academics to everyday dress has been to adopt what Davis has termed "fashion indifference" - a state in which ". . one is either oblivious to, or, for one reason or another, thoroughly unconcerned with what the reigning or ascendant fashion is." 34 Stereotypically, the (male) academic has dressed in baggy cords and a jumper or tweedy jacket. ${ }^{35}$ However, a closer examination of the everyday dress practices of the legal academics in my study reveals that both the variety of dress, and the conclusions to be drawn from its analysis, is more complex than might at first seem to be the case. Even clothing that says "I don't care what I wear" has a meaning - it does not say nothing. ${ }^{36}$

The first question about dress that I asked was "How do you choose what to wear to come to work?" Respondents used three terms to describe the style of dress they wore to work: "smart", "smart-casual" and "casual". Casual clothes, for both sexes, were jeans or chinos, worn with t-shirts, sweatshirts or a casual shirt. Smart-casual for men referred to slightly less casual trousers, worn with a smart shirt, and possibly an unstructured jacket. ${ }^{37}$ Women who described their dress as "smart-casual" defined this as wearing tailored trousers or a smart skirt and top which was not a t-shirt. Smart clothes for men meant a suit and tie; for women, suits (including trousersuits) or tailored outfits. There were no very significant differences in dress practices between people with different amounts of experience or working in different types of institution, merely a slight tendency for more experienced men to wear suits, and a slight tendency for those in old universities to be more casual. However, there were clear differences related to the gender of

Academe; what bothers professors?' (1996) 31 Higher Education p.471; and on the importance of gender see: Acker, Gendered Education (1994); Brooks, Academic Women (1997); Morley \& Walsh, Breaking Boundaries: women in higher education (1996).

32 McGlynn, The Woman Lawyer: making the difference (1998), p.41.

33 McGlynn, The Woman Lawyer: making the difference (1998), p.41

34 Davis, Fashion, Culture and Identity (1992), p.161.

35 Kaiser, Chandler \& Hammidi, 'Minding Appearances in Female Academic Culture' in Guy, Green \& Banim, Through the Wardrobe: women's relationships with their clothes (2001) at p.117.

36 Harvey, Men in Black (1995), p.11.

37 An unstructured jacket is a man's jacket which lacks the stiffening, shoulder pads and so on which traditionally gave the jacket its structure. This style of jacket is most famously associated with the fashion designer, Giorgio Armani and the suits he designed for the film American Gigolo; see Tungate Fashion Brands: branding style from Armani to Zara (2005), p.119. 
respondents. The largest group of respondents (nearly half of the total) described their style as "smart-casual"; this group contained slightly more women than men. Just over a quarter described themselves as dressing casually; there were significantly more men than women in this group. The "smart" dressers (just under a quarter of the total) included significantly more women than men. As these respondents said:

"I think the women almost always dress more smartly. When I think of people who wear casual clothes, they're always men."

(Lecturer, female, early-career, old university)

"I guess towards the casual end of the spectrum you'd be more likely to see a man in jeans than a woman."

(Principal lecturer, male, mid-career, new university)

“. . . male members of staff sometimes can look a bit untidy, myself included, perhaps, but female members of staff don't ever seem to look untidy..."

(Senior Lecturer, male, early career, new university)

“. . . you don't see women wandering around in tracksuits but you do occasionally see the men [doing that] - so there is a difference."

(Lecturer, female, early career, new university)

As I have argued elsewhere, it would appear that this data provides new empirical evidence of some of the ways in which women's experience of the workspace is different to that of their male colleagues, and shows how they frequently use dress in order to gain credibility in the masculine environment of the university law school which has strong associations both with rationality (a stereotypically masculine trait) and with law (also stereotypically associated with masculinity). ${ }^{38}$ The way in which they dress shows women attempting to overcome their corporeal differences from the "hallmark male" while retaining the stamp of authority. ${ }^{39}$ They tend to dress more smartly, since otherwise they find it harder to achieve the status of "authoritative knower" than their male counterparts, while men, inhabiting their "natural" environment, can dress casually without relinquishing authority or credibility. ${ }^{40}$

Looking at dress choice overall, it is clear that this culture is one in which some form of casual dressing is the accepted norm. This immediately differentiates the culture of legal academia from that of legal practice. As Richard Collier points out in his study of law firms' recruitment literature,

38 Cownie, Legal Academics: culture and identities (2004) chap.8. On the association of rationality and masculinity, see: Ross-Smith \& Kornberger 'Gendered Rationality? A Genealogical Exploration of the Philosophical and Sociological Conceptions of Rationality, Masculinity and Organization' (2004) 11.3 Gender, Work \& organization pp.280-305; on the association of law with masculinity in the context of the academy see: Wells 'Working Out Women in Law Schools' (2001) 21.1 Legal Studies pp.116-136 at p.119.

39 Cownie, Legal Academics: culture and identities (2004), chap.8.

40 Cownie, Legal Academics: culture and identities (2004), pp.54-58. 
"The legal profession shares with other workplace contexts the primary cultural norm of the post-war business and corporate sphere within western capitalist economies, as well as throughout the world; that is, the wearing of the business suit as a common visible marker of social respectability." ${ }^{11}$

Several respondents commented on the difference in dress codes between legal practice and legal academia, especially those who had experience of working as a practising lawyer.

"Probably when I first came here I was a bit uncertain about the way to dress. I'd never taught before. Now I know you can wear what you want. Shorts and t-shirts every day if you want."

(Senior Lecturer, male, mid-career, new university)

“. . . I think it's expensive, dressing at university! When I was in practice, all I needed was a couple of suits - which the tax man helped me with. My accountant got me one new suit a year which was tax-deductible. Because I can choose what I want to wear now, I tend to have more clothes, more different things..."

(Lecturer, male, early-career, new university)

"My dress is reasonably casual, and I don't feel the need to dress up in a suit as I would if I was a solicitor. I make some sort of effort not to be scruffy - like I'd wear jeans at home but not at work. But I don't try that hard."

(Lecturer, female, early-career, old university)

Commentators outside the legal academy often assume that legal academics are closely connected with legal practice themselves (perhaps as part-time practitioners) and that a law degree is a heavily vocational degree. ${ }^{42}$ However, legal academics themselves do not identify with legal practice in this way, and their dress practices reflect the fact that their cultural mores are much more closely aligned to those of the academy than those belonging to the very different culture of legal practice. ${ }^{43}$

\section{The Significance of Dress in the Culture of Academic Law}

Even though the culture of legal academia as a whole was casual, in terms of dress practices, clothes formed an important part of a significant number of

41 Collier, 'Be smart, be successful, be yourself . . .?: representations of the training contract and trainee solicitor in advertising by large law firms' (2005) 12.1 International Journal of the Legal Profession 51-92 at p.60.

42 See, e.g. Warnock, Universities: knowing our minds. What the Government should do about higher education (1989) p.12; equally, Becher \& Trowler have no hesitation in categorizing the discipline of law, along with education and social administration, as an applied social science and "functional, utilitarian, concerned with the enhancement of (semi) professional practice." (Becher \& Trowler, Academic Tribes and Territories (2001), p.36.

43 Legal academics in my study regarded the main purposes of legal education as broadly 'liberal', rather than vocational. See: Cownie Legal Academics: culture and identities (2004), p.78. 
the respondents' professional identities, and their "performance" as legal academics. This was made clear when they were asked whether they wore the same type of clothes at weekends or in the vacations as they did in term time. Half of them said that they wore different clothes when they were not in a work context. Unsurprisingly, this figure was made up of all the smart dressers, plus half of the smart-casual dressers (one might speculate, those at the smarter end of the smart-casual spectrum). All the casual dressers remained resolutely casual. Slightly more women than men, and slightly more academics working in new universities, wore different clothes at weekends; both of these variations seem to be explained by the existence of "smarter" smart-casual dressers, who tended to "dress down" at weekends. There were no significant differences in dress habits in terms of length of experience as academics.

"Yes, I dress a bit more casually at weekends and in the vacation. I just feel that there should be a difference between one's work and other things. One needs to appear a bit more professional - it doesn't mean a suit, but a little more professional when you come to work. .."

(Professor, male, mid-career, old university)

"I think I kind of have a view that this is work and home is home, and I want to try and - it's my way of keeping some separation between them, although I am very bad at that, because I take work home, and do work at home."

(Lecturer, female, early-career, old university)

“. . . I don't like wearing my work clothes out of work...my work clothes are my work clothes and my play clothes are my play clothes... although it's not absolute - I do sometimes wear my work clothes out of work - but it's generally the basis of a little distinction, a habit, of distinguishing between work and play, and having a different wardrobe."

(Lecturer, mid-career, female, new university)

"I also think it's an advantage to have a "work wardrobe" and a "free-time wardrobe", just psychologically, you can take those clothes off when you come home in the evening, and at the weekend you can enjoy dressing up, that can be part of your weekend. .."

(Lecturer, female, early-career, old university)

Putting on different clothes when going to work appeared to be an important part of the "performance" as legal academic for a significant number of respondents. As these responses illustrate, the maintenance of clear boundaries between "home" and "work" was very important for some, and clothing played a significant role in achieving this goal. However, the very indeterminacy of the academic job, in terms both of time and commitment, 
makes it very difficult for academics to maintain clear temporal and spatial boundaries between "work" and "home". ${ }^{44}$

\section{The Casual Dressers}

At first glance, it would appear that dress did not play a significant role in the professional identities of the "casual dressers". Most of them denied any interest in clothing at all:

"Well, I'm not a very good clothes-y sort of person; I normally just wear what's on the chair. .."

(Senior Lecturer, male, mid-career, old university)

“. . . By and large, I wear what's comfortable, and don't worry too much about what it is..."

(Senior Lecturer, male, mid-career, new university)

Arguably, however, everyday dress plays just as significant a role in the construction of the professional identities of these respondents as it does for respondents who show more obvious interest in what they wear. Evidence of this can be found in the fact that, although they were unanimous in saying that they hardly ever altered their dress style, the casual dressers frequently identified occasions on which they would dress more smartly. These would almost always be occasions on which respondents would encounter "outsiders". In addition to illustrating the importance of dress, even for casual dressers, these practices also illustrate the way that individual dress choice is highly influenced by social/structural forces, as Bourdieu and Entwistle would suggest. 45

“. . . I've done some media work over the years, and that's caused me every now and then to rush out and buy something if I thought it would be more appropriate, but on the whole I've got away with what I wear, which suits me."

(Senior Lecturer, male, experienced, old university)

“. . . I recognise there are occasions when it's appropriate to be smart and wear a suit...First and foremost if I was representing the institution (either the law school or the university) to an outside group of people. I've also worn suits to things like inaugural lectures, where it's clearly very important to the person themselves, they've put a lot of work and effort into a public lecture - it's politeness, really, in that situation."

(Lecturer, early career, male, old university)

". . . if I am involved in one of the open days then I would dress more smartly. When you have potential students coming

${ }^{44}$ Collier, 'The changing university and the (legal) academic career: re-thinking the relationship between women, men and the 'private life' of the law school' (2002) 22.1 Legal Studies p.1-32 at p.21.

45 Entwistle, 'The Dressed Body' in Entwistle \& Wilson Body Dressing (2001), at p.37; Bourdieu; The Field of Cultural Production: essays on art and literature (1993). 
along, and you want to create a reasonably favourable impression, and I don't want to seem disrespectful to them. .."

(Senior Lecturer, male, early-career, new university)

The propensity to "dress up" for interaction with "outsiders" was a tendency shared by the "smart-casual" dressers, so that overall the result is that the majority of respondents agreed that "outsiders" are presented with a particular image of an academic lawyer - looking remarkably like a lawyer in practice. This consciously managed performance gives the impression to those outside the law school that academic lawyers are much more like stereotypical image of a city lawyer than they actually are. Evidence from other parts of my research suggests that the concerns of legal academics are increasingly focused on the demands and pressures of the academy, rather than those of the legal profession, so that the outsiders who see smartlydressed legal academics looking like the stereotypical solicitor are being given, to some extent at least, a misleading impression of the culture of legal academia ${ }^{46}$ This is a clear example of Goffman's "impression management", and, in particular, an example of "idealisation", where performers are offering observers a performance that is idealised, in the sense that it "highlights the common official values of the society in which it occurs". ${ }^{47}$ It would appear that these legal academics are bowing to the wider societal norms which (in contrast to the academy) equate scruffy dressing with low status. They are like the individuals described by Goffman who are presenting a product to others; in this situation, the audience will be led into judging the performer "on the basis of something that has been finished, polished and packaged." 48 This is made explicit in responses such as these:

"I think there is a tendency for a number of staff to dress up if they think they're going to come into contact with parents. . . I think there is a factor these days that we are trying to recruit people, so we're trying to impress, whereas - I did admissions here twenty years ago, and in those days we were selecting, not recruiting, and I don't think people necessarily did make the effort on open days then that they might do now to try and create the expected image of them as perceived by the "customer", if I can put it that way."

(Reader, male, experienced, old university)

“. . . The only time I put on something special is if I'm externalling, going to the Law Society or QAA, that sort of work. I'd dress up a bit, and I'd certainly make sure my shoes were polished, and put a jacket on ..."

(Senior Lecturer, female, mid-career, new university)

However, it is important to understand the subtlety of the "impression management" which is taking place here. These respondents reflect a culture where one does not go too far in the "dressing up" stakes - people dress "a bit more smartly", in keeping with the stereotypical academic norms that appearance is unimportant. The result is that suits may be worn, but they may

46 Cownie, Legal Academics: culture and identities (2004), pp.54-58.

47 Goffman, The Presentation of Self in Everyday Life (1990), p.45.

48 Goffman, The Presentation of Self in Everyday Life (1990), p.52. 
not be particularly expensive (Marks and Spencer, not Armani) and they may not be very fashionable. They are not a carbon copy of the sharp suits found in legal practice, but an academic version of the suit (which might also encompass a smart jacket and trousers, as opposed to a matching suit). It is also noticeable that the casual dressers, in contrast to the smart-casual and smart dressers discussed below, appear to rely primarily on their own judgement about the appropriate clothes to wear, rather than being concerned about how others will see them. Nevertheless, social pressures do bring about a change in their everyday dress practices, and their propensity to dress up for outsiders is a clear example of the interaction of individual choice and social forces which is stressed by Entwistle and Goffman.

Wearing casual dress in law schools is strongly gendered, not only because male legal academics are more likely to wear casual clothes to work, but because of the effect of the dress choices being made. Men who dress in casual clothes are, in the context of the academy, reinforcing their identification with the idea of rationality, though the same is not true for women. As Kaiser et al comment:

"The idea that the world of clothing and fashion is distinct from the life of the mind has a long and deeply gendered history in modern western culture. . . the dominant "disconnect" between the mind and the body has placed women in the position of "choosing" between thinking and appearing. This false, oppositional choice has persevered with tenacity, in part because it reifies dominant gendered power relations. Viewed from this lens, academic women embody and represent a contradiction in terms. .. $" 49$

Outside the academy (in legal practice, for example) dressing casually might be seen as less authoritative, a sign of low status. However, within the academy, it would appear that the prevailing norms are different, and that casual dress reflects the (male) wearer's disdain for the frivolous (fashion) and for physical appearance (unimportant, as compared with things of the mind). This concern with "higher things" appears to have close connections to the concept of rationality, which is a key aspect of the academy. But rationality itself is not necessarily a neutral concept. Indeed Ross-Smith and Kornberger argue powerfully that it is gendered in its core assumptions, and that Western rationality is masculine rationality.

"Abstract thought, objective judgement or general principles are seen as masculine characteristics, whereas subjectivity, emotions and orientation towards the concrete are understood as female. . . This separation is not equal, but organized in a hierarchical relation of subordination" 50

49 Kaiser et al 'Minding Appearances in Female Academic Culture' in Guy et al (eds.) Through the Wardrobe: women's relationship with their clothes (2001), at p.117.

50 Ross-Smith \& Kornberger, 'Gendered Rationality? A Genealogical Exploration of the Philosophical and Sociological Conceptions of Rationality, Masculinity and Organization' (2004) 11.3 Gender, Work \& Organization 280-305 at p.282. 
In terms of everyday dress, this would suggest that male legal academics who dress casually are merely strengthening their identification with some of the key (masculine) values of academia, and reinforcing their claim to "belong". 51 On the other hand, women who dress casually do not obtain the same benefit, because, by dressing casually, their dress usually works against strongly-held societal norms which dictate that women should be feminine. As Eileen Green notes in her study of the dress practices of female professors, women academics are faced with the need to present themselves as ". . . professional, authoritative, "substantial" selves who are at the top of their subject field, while also signalling what are perceived to be acceptable levels of femininity". ${ }^{52}$ If women make dress choices which challenge the accepted societal norms (by dressing very casually to go to work, for instance) this can easily serve to undermine their credibility, rather than facilitate acceptance and reinforce their position, as it does for men. In their study of professional women, Johnson et al tell the story of a female senior manager in an accounting firm who was denied partnership.

"In evaluations fatal to her promotion, partners described her as "macho, harsh and aggressive", speculating that she might have overcompensated for being a woman. In fact, one male supporter advised her to "walk more femininely, talk more femininely, dress more femininely, wear make-up, have her hair styled and wear jewellery." 53

Although this sort of reaction would be unlikely to be expressly stated in the context of a university law school, it remains true that overtly challenging societal "dress codes" can diminish a woman's authority, even in academia. Thus, while the casual dress codes found in the legal academy may appear to signal that both men and women have considerable freedom in their choice of clothes, it is arguable not only that women are much more constrained in their dress choices, but that the casual dress worn by male academics reinforces their dominant place in the law school.

\section{The Smart-Casual Dressers}

Half of the smart-casual dressers dressed differently at weekends to the way in which they dressed to come to work. For these people, clothes played a clear role in the construction of their professional identity and their "performance" as "legal academic".

". . . I like the idea of looking a bit smarter than perhaps I do when I'm at home - I mean, I wouldn't go out to the pub dressed like this, basically..."

(Lecturer, early-career, female, new university)

51 See: Wells, 'Working Out Women in Law Schools' (2001) 21.1 Legal Studies 116-136 at p.119.

52 Green, 'Suiting Ourselves: women professors using clothes to signal authority, belonging and personal style' in Guy, Green \& Banim, Through the Wardrobe: women's relationships with their clothes (2001) at p.99.

53 Johnson, Crutsinger, Workman, 'Can Professional Women Appear Too Masculine? The Case of the Necktie' (1994) 12(2) Clothing \& Textiles Research Journal 27-31, at p.27. 
"Oh yes, [I dress differently at weekends and in the vacations], it's part of the joy of being an academic. I can slob, can't I? Which, when I was in practice - perhaps for one's two week summer holiday, you know, but you never had long enough to feel really what it was like.... "

(Lecturer, early-career, male, new university)

“. . . I do think it's important when you're interfacing with the students to look professional. We are professionals, we want to be treated as professionals, and I think there's therefore a case for acting and looking like that - to a degree. That doesn't mean I am coming in wearing my court suit every day. But, you know, there's a difference between coming in and wearing my jeans and trainers, as I might do if I'm just me, and I'm just researching all day, or if I'm teaching and standing up in front of a group of sixty students. Why should they pay any attention to me if I just look like I've come in from the pub?"

(Lecturer, female, early-career, old university)

These respondents are consciously constructing their identities as "law lecturer", thinking about their interaction with students and the way in which they wish to present themselves. It is noticeable that the smart-casual dressers, in contrast to the casual dressers, are more concerned with the way in which they are seen by others. It would appear that they view casual dressing for work as unacceptable, appearing to assume that if they dressed casually, they would be viewed negatively (particularly students). There may be some evidence for their assumptions - in a recent poll, students complained that their lecturers are "Stuck-up, disorganised and unclean, with terrible dress sense and illegible handwriting." 54

Although it was not only women who made conscious dress choices as part of their performance as legal academic, the relationship of women to everyday dress choice appears to be significantly more complex than that of men. Green, in her study of the dress choices of female professors, argues that the clothes choices made by women in academia are part of a complex social process:

"Outfits are put together with an eye for the necessity of deference to the formal dress code of professional contexts but are also motivated by a strong desire to signal originality and difference via womanly bodies which challenge the male "suits" and avoid senior women being taken for secretaries or junior administrators" 55

This idea of the complexity of the choices made by women was emphasised by the respondents in my study, when I asked them "Do you think that choosing what to wear to come to work is different for men and women?" The majority of respondents agreed that dressing for work is different for men and women. There were no significant differences as between male and

54 THES 27.1.06, 'My Prof is a bit stinky, snooty and very unhip'.

55 Green, 'Suiting Ourselves: women professors using clothes to signal authority, belonging and personal style' in Guy et al (eds.), Through the Wardrobe: women's relationships with their clothes (2001), at p.104. 
female respondents, those working in old or new universities or those with varying amounts of experience. What the majority of respondents emphasised was that, in their view, the choices around dress for men are much more straightforward than they are for women.

"...I suspect it is more difficult for women. What does a man have to do? A man has to simply put a jacket on and button down their shirt and perhaps put a tie on, and you've got the difference between casual and formal. It must be a very difficult choice for a woman..."

(Principal lecturer, male, mid-career, new university)

"I think women have more problems in choosing what to wear - they haven't got what I would call the "cop-out" of wearing a suit like a bloke has. I mean, if a bloke wears a suit - most suits are of a similar kind and type, you know - so you wear a suit and as long as your tie isn't too flashy, basically, that's it, that's all you have to think about . . . but women don't have the equivalent of a work suit - I mean, I know there are suits that women wear, but there are many different types . . . I think it must be a nightmare for women, dressing for work . . I mean, just from what I observe from my partner (who's female) and the difficulties she has to "get it right" - I think it must be really difficult. .."

(Senior Lecturer, male, mid-career, old university)

“. . . The older men don't give much thought to what they wear, but I don't think they need to give such thought because if you're wearing a pair of trousers and a shirt as a man in your 40 s or 50s you can get away with almost anything in that outfit - whereas for a woman, younger or older, to be wearing just a casual pair of trousers and a shirt - I think you look more casual for some reason. .."

(Lecturer, female, early-career, old university)

"I think for men it's much easier to look formal - they just stick a tie on, and everyone knows: "Ah, yes, we're in serious dress mode." I think for women it's trickier, isn't it?. .."

(Senior Lecturer, male, mid-career, old university)

It appears that the complexity to which these respondents refer is brought about by the particular difficulties, for women, of managing a "smart-casual" style. Rucker et al note that once workplace dress codes shift in the direction of casual dress, it makes the construction of a powerful image much more complex than if it were possible merely to rely on the suit. ${ }^{56}$ This is a particular problem for women, who do not physically represent the stereotypical (male) academic, and are also denied the possibility of using the business suit in order to approximate to the male authority figure. Women have to constantly maintain the balance which Eileen Green pointed to in her study of the dress practices of female professors: to present

56 Rucker, Anderson \& Kangas, 'Clothing, Power and the Workplace' in Johnson \& Lennon (eds.) Appearance and Power (1999), p.60. 
themselves simultaneously as "professional" and "feminine" in a way which is not true for men - since "being professional" is, as it were, "built in" to the modes of dress adopted by men in the academy. ${ }^{57}$ Once we understand everyday dress in law schools to be mediated through the culture of the (masculinised) academy, then any attempt to express the "othered" female identity can be seen to be loaded with meaning about how the wearer sees the relationship between herself and the academy, and it is this complexity which is reflected in the respondents' comments.

\section{The Smart Dressers}

All except one of the smart dressers dressed differently at weekends to the way they dressed to come to work. Dress played a significant role in the creation of their professional identity. For all the smart dressers, as for the smart-casual dressers, the image of "legal academic" was associated with dressing more smartly. This was as true when they were interacting with students as when they were considering other aspects of their professional life.

"I wouldn't come to work in jeans, unless it was the weekend I have a friend who says "You never know who'll ask you out to lunch", and I think that's a good reply, but, for me, it isn't quite that reason. Maybe it goes right back to when I first started teaching, in a school. I went to uni when I was incredibly young, probably some of the people I was teaching looked older than me, and I always made a point, then, of looking like I was the teacher, and then you just get into the habit. It isn't that reason any more. I just guess I like to look smart."

(Reader, female, mid-career, old university)

"Oh, yes, I dress differently as soon as I go home. The first thing I do is throw it all off and put something comfortable on. And during vacation, too - though if I have a meeting, I'll put on a suit."

(Professor, male, experienced, old university)

“. . . I also think it's an advantage to have a work wardrobe and a free-time wardrobe, just psychologically. You can take those clothes off when you come in in the evening, and at the weekend, well, you can enjoy dressing up - that can be part of your weekend. And just to reserve some clothes for work - I think you feel more workmanlike as well - you know how some London firms have tried to introduce dressing down days and found it was less productive, and they're emailing each other all the time and they can't take the job seriously - well, that struck me as perfectly understandable ... I like to get up in the morning, and dress in clothes that make me feel I'm going to work."

57 Green, 'Suiting Ourselves: women professors using clothes to signal authority, belonging and personal style' in Guy, Green \& Banim, Through the Wardrobe: women's relationships with their clothes (2001), at p.99. 


\section{(Lecturer, female, early-career, old university)}

Looking at the responses of the "smart dressers", I want to explore these data further, by examining some of the ways in which everyday dress choices constitute one of the social practices which contribute to the continuing marginalisation of women in the legal academy. As Collier notes, the "masculine culture" of the law school is heterogeneous, encompassing a plurality of masculinities. What these masculinities share is a social positioning which, by virtue of being a sexed man, is constructed as having at least the potential to make claims to the status of "authoritative knower". ${ }^{58}$ The benefits for men of being identified with the dominant masculinity derive from the social power it confers, the various attributions of mastery it elicits from others. ${ }^{59}$ Everyday dress is arguably one of those social practices which systematically privileges men, and in his aptly-titled article, "“"Nutty Professors" "Men in Suits" and "New Entrepreneurs": corporeality subjectivity and change in the law school and legal practice." Collier identifies the business suit as exemplifying "a broadly hegemonic masculine style." ${ }^{60}$ His reading of the suit is that it serves two critical functions: it "desexualises" the male body, in terms of erasing the sexed specificity of the male body, and it thereby constitutes men as neutral conduits of legal knowledge. ${ }^{61}$

I would agree with Collier that the constitution of masculine bodies and subjectivities can be seen as important factors in the production and maintenance of the normative constructs of social, economic and cultural capital which tend to marginalize and discriminate against women in the law school. However, I wish to offer a different reading of the role of the male suit in this culture. Another reading of the effect of the suit in the legal academy might be that the ability of men to be dominant in the masculinised world of law is not dependent upon a denial of men's sexed corporeality, but rather that it involves reinforcing their heterosexual masculinity, and that the suit plays an important role in achieving this. Even Hollander, whose work Collier himself refers to, notes that suits ". . . express a confident adult masculinity", while McCracken sees the suit as having an intensely masculine sexual charge. ${ }^{62}$

I would argue that the business suit worn by men is highly sexualised. Suits, with their broad shoulders and slim hips emphasise masculinity. They do not look overtly "sexy", which would detract from authority, but that does not

58 Collier, "Nutty Professors" "Men in Suits" and "New Entrepreneurs"; corporeality subjectivity and change in the law school and legal practice. (1998) 7 Social \& Legal Studies pp.27-53 at p.40.

59 Waldby, 'Destruction: boundary erotics and the refigurations of the heterosexual male body' in Grosz \& Probyn (eds.), Sexy Bodies: the strange carnalities of feminism (1995), p.271.

60 Collier, "Nutty Professors" "Men in Suits" and "New Entrepreneurs"; corporeality subjectivity and change in the law school and legal practice. (1998) 7 Social \& Legal Studies pp.27-53 at p.33.

61 See also: Thornton, Dissonance and Distrust: women in the legal profession (1996), p.216.

62 Hollander, Sex and Suits: the evolution of modern dress (1994), p.112; McCracken, 'The Trickle-Down Theory Rehabilitated' in Solomon (ed.), The Pyschology of Fashion (1985), p.48. 
mean they are "de-sexed". In his detailed analysis of the suit, Flusser points to the different suit silhouettes which arose during the twentieth century from different "schools" of tailoring. The British style modelled itself along the lines of a military uniform, as exemplified by the long-fitting hourglassshaped hacking jacket. His description serves to emphasise the way in which suits were designed to emphasize the wearer's masculinity:

"Adhering closely to the body, with subtle emphasis on the chest and a soft shoulder, the silhouette's marked waist, slightly flared skirt and deep side vents, trimmed sleeves and trouser line gave a man a firm, almost regal bearing, especially if he happened to be aristocratically slender." 63

Turning to the Continental or European style, the ability of the suit to emphasize the wearer's masculinity is even clearer. The traditional European cut was:

". . . characterised by high squarish shoulders and a short overall length, the jacket demanded small, high armholes to give the chest the length that the jackets denied it. Cut close through the chest and hips...its trousers had a lower rise with figure-hugging legs. The European's wedge-like torso and lean-fitting trousers turned many a young male into a walking phallic symbol." 64

My reading of the suit is much closer to that of Flusser than that of Collier. I see the male business suit as a sexualised garment, which emphasises stereotypically masculine qualities, and in doing so, reinforces the position of the hegemonic male. As Edwards comments:

". . . the suit is as much a symbol of masculine sexuality in terms of broadening shoulders and chest and connecting larynx to crotch through collar and tie as it is a practical (if historically uncomfortable) uniform of respectability." 65

However, it is also important to acknowledge the variety of male suits which it is possible to wear, most notably the "business suit" and the unstructured or casual suit. There are important signals of non-conformity and even subversion which the male wearer can convey through the cut, fabric and style of the casual suit, particularly when worn on formal occasions. Unstructured jackets in light or "earthy" tones, baggy trousers, open-necked shirts and supple linen or cotton fabrics "soften" the male silhouette, whereas the dark colours, broad padded shoulders, heavy fabrics and stiff lapels of the business suit "harden" the silhouette. If, like Entwistle, we understand dress to represent "the visible envelope of the self", ${ }^{66}$ then men who have a preference for dressing in unstructured suits could perhaps be suggesting that the boundary between their (males) selves and (female) others is less rigid and well-defined than the man who dresses in the business suit. Wearing an

${ }^{63}$ Flusser, Dressing the Man: mastering the art of permanent fashion (2002), p.80.

${ }_{64}$ Flusser, Dressing the Man: mastering the art of permanent fashion (2002), p.81.

65 Edwards, Men in the Mirror: men's fashion, masculinity and consumer society (1997), p.3.

66 Entwistle, 'The Dressed Body' in Entwistle \& Wilson, Body Dressing (2001), at p.57. 
unstructured suit could be interpreted as a subtle act of repudiating some of the "baggage" associated with being male in a culture of intellectual machismo, while simultaneously adhering to some of its conventions. These subtleties of dress reflect the different masculinities found in the law school, some diverging greatly from hegemonic masculinity, some closely adhering to it. In doing so, they reinforce the importance of "performance" as a way of theorising dress practices in the law school.

Some of the female "smart dressers" also wore suits, reflecting the strategy common among professional women of wearing a version of the male business suit in order to suggest that they, as much as men, possess the requisite qualities for success in their chosen field. ${ }^{67}$ There are, of course, many versions of the female suit - some of them much closer to the masculine model than others - merely wearing a suit cannot guarantee that the (female) wearer overcomes her "otherness". Green notes that her female professors' narratives were "threaded through with the contradictions involved in feeling vulnerable and exposed as otherly bodies in a masculine academy, while celebrating their embodied differences as women." 68

The importance of the suit in legal academia should not be over-emphasised. Only a minority of my male respondents habitually wore suits (and with few exceptions they were over 35). Most other male legal academics wore suits only on specific occasions. Nevertheless, for a man, the effect of wearing a suit remains the same, whatever the occasion; it effortlessly reinforces masculine claims to authority. Denied this straightforward relationship between dress and authority, women's dress choices are much more complex.

\section{Conclusion}

"Dress is neither culturally nor politically neutral. It is loaded with significance. Clothes are stuff that "speaks volumes." 69 In his analysis of the importance of the freedom to dress as we choose, William Keenan makes a powerful argument for the importance of protecting dress freedom, reminding us that "Whenever enforced dress codes are employed as a deliberate instrument of repression, torture and dehumanization, we are in an order of things where civilization is at risk."70

"...we should value that most individual and personalized of freedoms, dress freedom, and seek to nurture it and safeguard it when we can in the wider interest of individual liberty within

67 Johnson, Crutsinger \& Workman, 'Can Professional Women Appear Too Masculine? The Case of the Necktie' (1994), 12(2) Clothing \& Textiles Research Journal pp.27-31 at p.27.

68 E. Green, 'Suiting Ourselves: women professors using clothes to signal authority, belonging and personal style' in Guy et al (eds.) Through the Wardrobe: women's relationships with their clothes (2001), at p.113.

69 Keenan, 'Dress Freedom: the personal and the political' in Keenan (ed.) Dressed to Impress: looking the part (2001), at p 181

70 Keenan, 'Dress Freedom: the personal and the political' in Keenan (ed.) Dressed to Impress: looking the part (2001), at p.188. 
the open society. It requires eternal vigilance, no less so than other rights and freedoms with which dress liberty is intimately connected, such as are associated with freedom of conscience, freedom of expression, and free expression of personal beliefs... a high tolerance of diversity of dress expression is a measure of our practical commitment to a democratic, open society. .."71

In the context of the university, where dress freedom is generally taken for granted, it is easy to overlook the fact that the apparent free choice of individuals to dress as they please is actually a matter of complex negotiation between different individual and social forces. Examining the results of these negotiations (the dress choices made on a day-to-day basis) tells us much about the way that the working lives of legal academics are played out. Although the culture of the law school, as regards dress, is predominantly casual and self-consciously different from legal practice, this apparently laidback attitude hides considerable complexities. "Outsiders" are very unlikely to be given an accurate picture of the habitual everyday dress of legal academics. The impression they get is highly managed, to ensure that a professional image, which speaks to them of the lawyer in private practice, is conveyed. However, the everyday dress culture which can be found in what Trow refers to as the "private life" of the academy is much more informal than that found in legal practice, and the majority of legal academics do not identify closely with the legal profession. ${ }^{72}$

In the law school, as in other workspaces, dress speaks of gender, and power. Perhaps what is significant about the data from my research is the way in which it reveals that, whether dressed casually or in a business suit, men are able, through their everyday dress, to reinforce the claims of the multiple masculinities found in law schools to the status of "authoritative knower". They can do this by adopting the casual, "non-fashion" approach, demonstrating that their claim to be authoritative is so strong that they do not need to reinforce it with dress choice - indeed, their adoption of dress which could be thought to undermine their authority has, in some ways, the opposite effect in academia, where it fits in so well with the Cartesian mindbody dualism. Or they can adopt the smart approach, and wear a suit - in which case, they get all the benefits so clearly described by Thornton, in her study of the legal profession:

"In our society, it is a man in a dark suit, plain shirt, unostentatious tie, with a neat haircut and beardless face who is most commonly equated with the image of impersonal authority. ...73

71 Keenan, 'Dress Freedom: the personal and the political' in Keenan (ed.) Dressed to Impress: looking the part (2001), at p.180.

72 Trow, 'The Public and Private Lives of Higher Education' (1975) 104 Daedalus pp.113-127.

73 Thornton, Dissonance and Distrust: women in the legal profession (1996), p.223. 